University of Nebraska - Lincoln

DigitalCommons@University of Nebraska - Lincoln

2-14-2016

\title{
Breed effects and genetic parameter estimates for calving difficulty and birth weight in a multibreed population
}

\author{
C. M. Ahlberg \\ University of Nebraska - Lincoln
}

L. A. Kuehn

Roman L. Hruska U.S. Meat Animal Research Center

R. M. Thallman

Roman L. Hruska U.S. Meat Animal Research Center

S. D. Kachman

University of Nebraska - Lincoln, steve.kachman@unl.edu

W.M. Snelling

Roman L. Hruska U.S. Meat Animal Research Center

See next page for additional authors

Follow this and additional works at: https://digitalcommons.unl.edu/hruskareports

Ahlberg, C. M.; Kuehn, L. A.; Thallman, R. M.; Kachman, S. D.; Snelling, W.M.; and Spangler, Matthew L., "Breed effects and genetic parameter estimates for calving difficulty and birth weight in a multibreed population" (2016). Roman L. Hruska U.S. Meat Animal Research Center. 448.

https://digitalcommons.unl.edu/hruskareports/448

This Article is brought to you for free and open access by the U.S. Department of Agriculture: Agricultural Research Service, Lincoln, Nebraska at DigitalCommons@University of Nebraska - Lincoln. It has been accepted for inclusion in Roman L. Hruska U.S. Meat Animal Research Center by an authorized administrator of DigitalCommons@University of Nebraska - Lincoln. 


\section{Authors}

C. M. Ahlberg, L. A. Kuehn, R. M. Thallman, S. D. Kachman, W.M. Snelling, and Matthew L. Spangler 


\title{
Breed effects and genetic parameter estimates for calving difficulty and birth weight in a multibreed population ${ }^{1}$
}

\author{
C. M. Ahlberg, ${ }^{*}$ L. A. Kuehn, $\dagger$ R. M. Thallman, $\uparrow$ S. D. Kachman, $\$$ W. M. Snelling, $\uparrow$ and M. L. Spangler*2 \\ *Department of Animal Science, University of Nebraska - Lincoln, Lincoln 68583; \\ †USDA, ARS, Roman L. Hruska U.S. Meat Animal Research Center, Clay Center, NE 68933; \\ and \$Department of Statistics, University of Nebraska - Lincoln, Lincoln 68583
}

\begin{abstract}
Birth weight (BWT) and calving difficulty (CD) were recorded on 4,579 first-parity females from the Germplasm Evaluation Program at the U.S. Meat Animal Research Center (USMARC). Both traits were analyzed using a bivariate animal model with direct and maternal effects. Calving difficulty was transformed from the USMARC scores to corresponding $Z$-scores from the standard normal distribution based on the incidence rate of the USMARC scores. Breed fraction covariates were included to estimate breed differences. Heritability estimates (SE) for BWT direct, CD direct, BWT maternal, and CD maternal were 0.34 (0.10), $0.29(0.10), 0.15(0.08)$, and $0.13(0.08)$, respectively. Calving difficulty direct breed effects deviated
\end{abstract}

from Angus ranged from -0.13 to 0.77 and maternal breed effects deviated from Angus ranged from -0.27 to 0.36. Hereford-, Angus-, Gelbvieh-, and Brangus-sired calves would be the least likely to require assistance at birth, whereas Chiangus-, Charolais-, and Limousinsired calves would be the most likely to require assistance at birth. Maternal breed effects for CD were least for Simmental and Charolais and greatest for Red Angus and Chiangus. Results showed that the diverse biological types of cattle have different effects on both BWT and CD. Furthermore, results provide a mechanism whereby beef cattle producers can compare EBV for $\mathrm{CD}$ direct and maternal arising from disjoined and breed-specific genetic evaluations.

Key words: beef cattle, breed effects, calving difficulty

(C) 2016 American Society of Animal Science. All rights reserved. J. Anim. Sci. 2016.94:1857-1864 doi:10.2527/jas2015-0161

\section{INTRODUCTION}

Calving difficulty (CD; dystocia) is a significant cost to beef production and is most prevalent in firstcalf heifers. Dystocia increases the likelihood of calf and dam mortality, postpartum interval, and labor and veterinarian costs (Bennett and Gregory, 2001). Expression of CD is affected by both direct (calf) and maternal (dam) genotypes. Factors affecting CD include age of dam, sex of calf, shape and weight of calf,

\footnotetext{
${ }^{1}$ Mention of a trade name, proprietary product, or specific equipment does not constitute a guarantee or warranty by the USDA and does not imply approval to the exclusion of other products that may be suitable. The USDA is an equal opportunity provider and employer.

${ }^{2}$ Corresponding author: mspangler2@unl.edu

Received December 2, 2015.

Accepted February 14, 2016.
}

gestation length, breed, sire of calf, pelvic area of dam, and weight of dam (Brinks et al., 1973). The genetic correlation between CD and birth weight (BWT) is positive and moderate to high in magnitude; therefore, selection to decrease BWT can be used to reduce CD (Bennett and Gregory, 2001). However, assuming the same selection accuracy, direct selection on the economically relevant trait of CD would be more efficient. Unfortunately, an antagonistic relationship between $\mathrm{CD}$ direct and maternal genetic effects has been reported $(-0.26$; Bennett and Gregory, 2001); therefore, the inclusion of both CD direct and maternal EBV in a breeding objective is warranted.

Breed utilization allows for the exploitation of heterosis and complementarity to match genetic potential with markets, feed resources, and climates (Cundiff et al., 1998). However, in the current U.S. beef industry, it is generally not possible to directly compare EBV of animals across breeds without the aid of adjustment 
factors. Across-breed adjustments were first developed by Notter and Cundiff (1991) and are updated annually given changes in genetic trends and base adjustments (Van Vleck et al., 2007). Across-breed adjustment factors have most recently been estimated by Kuehn and Thallman (2014) for BWT, weaning weight, yearling weight, maternal milk, marbling score, rib eye area, fat thickness, and carcass weight. Unfortunately, acrossbreed adjustment factors do not exist for CD.

Consequently, the objectives of this study were to estimate breed differences for direct and maternal CD for first calf heifers in the U.S. Meat Animal Research Center (USMARC) Germplasm Evaluation (GPE) Program as a first step toward the development of across-breed adjustment factors for $\mathrm{CD}$.

\section{MATERIALS AND METHODS}

\section{Animals}

All animal procedures followed USMARC standard operating procedure (as no experimental protocols were applied) and cattle were treated according to Federation of Animal Science Societies guidelines (FASS, 1999). Pedigree and performance data originated from the GPE Program at the USMARC (Clay Center, NE; 1970-2012). The breeds used and the mating procedures used for each of the 8 cycles were previously reported by Smith et al. (1976; Cycle I), Gregory et al. (1978; Cycle II), Arango et al. (2002; Cycle III), Cundiff et al. (1998; Cycle IV), Wheeler et al. (2001; Cycle V), Wheeler et al. (2004; Cycle VI), Cushman et al. (2007; Cycle VII), and Wheeler et al. (2010; Cycle VIII). Briefly, in each cycle, 5 to 7 breeds of sire, sampled to represent industry germplasm, were mated to base Angus, Hereford, or MARC III (one-fourth Angus, one-fourth Hereford, one-fourth Pinzgauer, and one-fourth Red Poll) cows. Hereford and Angus bulls were used in each cycle as a base comparison. Comparisons of the breeds in this project were primarily facilitated through data from Cycle VII and from more recent continuous sampling of industry bulls (continuous GPE). In Cycle VII of the USMARC GPE project, purebred Angus, Hereford, Red Angus, Charolais, Gelbvieh, Simmental, and Limousin sires were mated by AI to Angus, Hereford, and composite MARC III cows to produce progeny designated as $\mathrm{F}_{1}$, born in 1999, 2000, and 2001. The 1999- and 2000-born male calves were castrated and fed for harvest. Female $\mathrm{F}_{1}$ and the 2001-born $\mathrm{F}_{1}$ males were kept for breeding and mated in multiplesire pastures to produce 2-, 3-, and 4-breed cross progeny designated $\mathrm{F}_{1}^{2}$. The $\mathrm{F}_{1}^{2}$ calves were born from 2003 to 2007 from 3-yr-old and older dams (Snelling et al., 2010). More recent GPE records were included from individuals that were of varying proportions of the 7 breeds used in Cycle VII produced through continuous sampling of industry sires from these breeds. For the more recent GPE generations (continuous GPE), purebred AI sires were mated to purebred or crossbred dams to generate purebred and crossbred steers and heifers and purebred and $F_{1}$ bulls. The $F_{1}$ bulls were mated to the purebred and half-blood females to produce purebred, half-blood, and $\mathrm{F}_{1}^{2}$ steers and heifers. All germplasm introduced into the population entered through AI. Animals from the 8 cycles included only spring-born records whereas the advanced generations of GPE included spring and fall calving records. All heifers were bred via natural service during GPE cycles. During continuous evaluation, heifers were bred via AI to sires that were minimally in the top half of their respective breed for either calving ease direct or BWT direct EBV, had high accuracy EBV, and represented heavily used sires in the U.S. industry. Those that did not conceive via AI were exposed to natural service Angus sires selected for calving ease direct EBV. The 18 breeds (number of AI sires) involved in the evaluation were Angus (131), Hereford (140), Red Angus (43), Shorthorn (52), South Devon (25), Beefmaster (44), Brangus (47), Brahman (57), Santa Gertrudis (21), Braunvieh (30), Charolais (100), Chiangus (24), Gelbvieh (73), Limousin (62), Maine-Anjou (38), Salers (50), Simmental (71), and Tarentaise (17).

Data were recorded for CD and BWT on 5,795 calves born to first-parity females in the GPE project. Reasons for removal from the final data set (proportion of those removed) were born with an abnormal presentation (12.2\%; e.g., breach), presented with cryptorchidism $(0.2 \%)$, born to a founder female or a twin (72.6\%), and born before 1970 (spring born; $0.6 \%$ ) or before 2007 (fall born; 14.4\%). These cutoffs represent the start dates of different phases of evaluation of GPE progeny. After edits, there were a total of 4,579 records. Cows were closely monitored for CD and were assigned a CD score as outlined in Table 1. Birth weights were recorded within $24 \mathrm{~h}$ after calving.

\section{Statistical Analysis}

Calving difficulty was transformed from the USMARC scores to the corresponding $Z$-scores from the standard normal distribution (Table 1) based on incidence rate of the USMARC scores. The midpoint value of the incidence rate between each subsequent USMARC score was used to assign $Z$-scores. For example, the incidence rate for category 1 was $74 \%$ and the incidence rate for category 2 was $2.3 \%$, making the midpoint value for category $137 \%$ (half of the incidence rate) and the midpoint value for category $275.1 \%$ (the midpoint between category 1 and category 2 ). The corresponding $Z$-scores for the first 2 categories were the 37 th and 75 th percentiles of 
Table 1. Description of calving difficulty score

\begin{tabular}{|c|c|c|c|c|}
\hline USMARC $^{1}$ score & $Z$-score ${ }^{2}$ & Difficulty level & Incidence rate & Midpoint value $^{3}$ \\
\hline 1 & -0.33 & No assistance given & $74 \%$ & $37.0 \%$ \\
\hline 2 & 0.68 & Little difficulty, assisted by hand & $2.3 \%$ & $75.1 \%$ \\
\hline 3 & 0.81 & Little difficulty, assisted by calf jack & $5.7 \%$ & $79.2 \%$ \\
\hline 4 & 1.18 & Slight difficulty, assisted by calf jack & $12 \%$ & $88.0 \%$ \\
\hline 5 & 1.62 & Moderate difficulty, assisted by calf jack & $1.5 \%$ & $94.8 \%$ \\
\hline 6 & 1.86 & Major difficulty, assisted by calf jack & $2.7 \%$ & $96.9 \%$ \\
\hline 7 & 2.35 & Caesarean birth & $1.8 \%$ & $99.1 \%$ \\
\hline
\end{tabular}

the standard normal distribution. Variance components and fixed effects were estimated using ASReml version 3.0 (Gilmour et al., 2009). The linear-linear animal model used to jointly analyze BWT and CD included fixed effects of sex, contemporary group (concatenation of year and season of birth and location of birth at the USMARC; $n=35$ ), and covariates for breed fractions, direct, and maternal heterosis. Random effects included direct and maternal additive genetic effects, and residual. The covariates for direct and maternal heterosis were allocated as the regression on expected breed heterozygosity fraction. For heterosis calculation, AI sires and commercial cows of the same breed were considered the same breed, Red Angus was assumed the same as Angus, and composite breeds were considered according to their nominal breed composition. Composite breeds consisted of MARC II (one-fourth Angus, one-fourth Hereford, onefourth Simmental, and one-fourth Gelbvieh), MARC III (one-fourth Angus, one-fourth Hereford, one-fourth Red Poll, and one-fourth Pinzgauer), Brangus (three-eighths Brahman and five-eighths Angus), Santa Gertrudis (three-eighths Brahman and five-eighths Shothorn), Beefmaster (one-half Brahman, one-fourth Angus, and one-fourth Shorthorn), Chiangus (one-half Chianina and one-half Angus), and one-half Red Angus- and one-half Simmental-cross cows. Breed fractions were determined based on pedigree information; each animal was assigned half of its sire breed and half of its dam breed. Founder animals, sires or dams with known breed but unknown parentage, were assigned to their respective breeds and used to assign breed fractions throughout the pedigree; for breed fraction covariates, AI sires and commercial cows of the same breed were considered different breeds. Breed fractions were then assigned for each individual and fit as covariates for the estimation of breed effects.

Birth weight and CD breed differences were deviated from Angus. Birth weight breed differences were adjusted to current (2012) breed mean EBV by accounting for the sampled AI sires through adding the sampling effect of sires to estimated breed effects. The sampling effect of sires was accounted for by estimat- ing the weighted (using average relationship to phenotyped progeny) average EBV of AI sires that had descendants with records, deviated from the mean EBV of their respective breed for calves born in 2012 using the following: $\operatorname{EBV}(i)_{Y Y}-\operatorname{EBV}(i)_{\text {USMARC }}$, which is the difference between the average within-breed EBV for breed $i$ to a base year (YY) of 2012 and the weighted average EBV for sires of breed $i$ that have descendants with records at the USMARC.

Calving difficulty breed differences were standardized by the following: BreedSoln $/ \sigma_{a}$, in which BreedSoln is the estimated breed effect solutions and $\sigma_{a}$ is the additive genetic SD estimated from the current analysis using GPE data from the USMARC. The standardized estimated breed effects were then corrected for sampling of AI sires. Sampling of AI sires were standardized to account for the differences in models used by breed associations in generating calving ease EBV by the following: $\left\{\left[\mathrm{EBV}(i)_{\mathrm{YY}}\right.\right.$ $\left.\left.-\operatorname{EBV}(i)_{\text {USMARC }}\right] \times-1\right\} / \sigma_{a(i)}$. Multiplication by -1 is necessary to convert calving ease EBV reported by beef cattle breeds in the United States report to CD EBV. The additive genetic SD $\left(\sigma_{a(i)}\right)$ was obtained from the SE of prediction and corresponding accuracy from each breed for calving ease direct and maternal EBV of each breed association. To put all breed estimates on the same scale, breed effects were then multiplied by either the direct (e.g., $\sigma_{a}$ ) or maternal additive SD from the current analysis for direct and maternal breed estimates, respectively.

\section{RESULTS AND DISCUSSION}

\section{Genetic Parameters}

Although not the primary aim, estimates of variance components for BWT and CD were obtained as a necessary step in estimating breed effects and developing across-breed adjustment factors for BWT and CD EBV. These variance components are presented in Table 2. Estimates of direct and maternal heritabil- 
Table 2. Residual, direct, and maternal (co)variance estimates for birth weight and calving difficulty

\begin{tabular}{|c|c|c|c|c|c|c|}
\hline 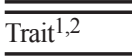 & 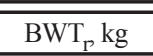 & $\mathrm{CD}_{\mathrm{r}}$ & $\mathrm{BWT}_{\mathrm{d}}, \mathrm{kg}$ & $\mathrm{CD}_{\mathrm{d}}$ & $\mathrm{BWT}_{\mathrm{m}}, \mathrm{kg}$ & $\mathrm{CD}_{\mathrm{m}}$ \\
\hline$\overline{B W T_{r}, k g}$ & $10.68(1.55)$ & & & & & \\
\hline $\mathrm{CD}_{\mathrm{r}}$ & $0.37(0.17)$ & $0.23(0.03)$ & & & & \\
\hline $\mathrm{BWT}_{\mathrm{d}}, \mathrm{kg}$ & & & $6.91(1.93)$ & & & \\
\hline $\mathrm{CD}_{\mathrm{d}}$ & & & $0.58(0.21)$ & $0.12(0.04)$ & & \\
\hline $\mathrm{BWT}_{\mathrm{m}}, \mathrm{kg}$ & & & $-0.75(1.52)$ & $0.26(0.19)$ & $3.03(1.59)$ & \\
\hline $\mathrm{CD}_{\mathrm{m}}$ & & & $0.07(0.21)$ & $0.01(0.03)$ & $-0.17(0.17)$ & $0.05(0.03)$ \\
\hline
\end{tabular}

${ }^{1} \mathrm{BWT}_{\mathrm{r}}=$ birth weight residual; $\mathrm{CD}_{\mathrm{r}}=$ calving difficulty residual; $\mathrm{BWT}_{\mathrm{d}}=$ birth weight direct; $\mathrm{CD}_{\mathrm{d}}=$ calving difficulty direct; $\mathrm{BWT} \mathrm{m}=$ birth weight maternal; $\mathrm{CD}_{\mathrm{m}}=$ calving difficulty maternal.

${ }^{2}$ Variances (SE) are on the diagonal and covariances are on the off diagonal.

ity for BWT and CD and their correlations are presented in Table 3. Mujibi and Crews (2009) reported a higher direct heritability estimate (0.46) and a similar maternal heritability estimate $(0.14)$ for BWT. Bennett and Gregory (2001) reported larger direct (0.43) and maternal (0.23) heritability estimates for CD using a linear-linear model in 2-yr-old females where CD was scored using 7 categories.

The genetic correlation between direct and maternal BWT from the present study $(-0.16)$ was similar to the correlation $(-0.27)$ obtained by Mujibi and Crews (2009), who used a 3-trait linear model including BWT, percent unassisted calving, and gestation length. Bennett and Gregory (2001) reported higher genetic correlations between CD and BWT direct (0.81) than reported in the present study (0.64) from a linear-linear model using 7 categories for $\mathrm{CD}$. The positive correlation between BWT direct and CD direct suggests that as BWT increases, CD score also increases, and the magnitude suggests that BWT breeding values explain approximately $41 \%$ of the genetic differences in CD. Bennett and Gregory (2001) reported a similar strength in correlation between BWT direct and CD maternal $(-0.16)$ but it differed in direction compared with the estimate from the current study (0.11); however, the estimate from the current study is not different from zero. Bennett and Gregory (2001) reported a stronger negative correlation between direct $\mathrm{CD}$ and maternal $\mathrm{CD}(-0.26)$ as opposed to the estimate of 0.10 from the current study. Both estimates were not significantly different from zero. A negative correlation between CD direct and maternal would be anticipated because calves born without difficulty tend to be smaller (evidenced by the 0.64 genetic correlation from the current study) and therefore are more likely to be smaller in mature size because the genetic correlation between BWT and mature weight has been estimated as moderate $(0.57$; Northcutt and Wilson, 1993). Moderate-size cows tend to have a smaller pelvis area and therefore have more difficulty when they calve during their first parity (Bellows et al., 1971). The antagonistic relationship between CD direct and maternal reported by Bennett and Gregory (2001) is supported by others (e.g., Mujibi and Crews, 2009; Eriksson et al., 2004) and suggests that direct selection for reduced CD could result in female progeny that have increased CD when they become dams. The unexpected positive estimate report herein, although not different from zero, could be an artifact of a mating design whereby sires were selected based on their genetic potential to reduce dystocia when bred to virgin heifers. The genetic correlation reported here between $\mathrm{CD}$ maternal and BWT maternal $(-0.42)$ suggests that females that have less $\mathrm{CD}$ will also have lighter calves. Eriksson et al. (2004) reported a positive correlation between CD maternal and BWT maternal for Charolais cattle (0.46) and a slightly negative correlation using Hereford data $(-0.28)$. Calves born with lighter BWT are smaller in size, having a higher probability of fitting through the cow's pelvis, and therefore are born with less difficulty. Bennett and Gregory (1996) reported a genetic correlation estimate of 0.14 between BWT direct and BWT maternal for composite breeds (MARC II and MARC III) and 0.08 for the purebreds that formed the composites compared with the estimate of -0.16 from the current study.

\section{Breed Effects for Birth Weight}

Adjusted breed effects for BWT are presented in Table 4. The breed solutions for BWT presented here

Table 3. Heritability and direct and maternal correlation estimates for birth weight and calving difficulty

\begin{tabular}{lrcrc}
\hline \hline Trait $^{1,2}$ & $\mathrm{BWT}_{\mathrm{d}}, \mathrm{kg}$ & $\mathrm{CD}_{\mathrm{d}}$ & $\mathrm{BWT}_{\mathrm{m}}, \mathrm{kg}$ & $\mathrm{CD}_{\mathrm{m}}$ \\
\hline $\mathrm{BWT}_{\mathrm{d}}, \mathrm{kg}$ & $0.34(0.10)$ & & & \\
$\mathrm{CD}_{\mathrm{d}}$ & $0.64(0.17)$ & $0.29(0.10)$ & & \\
$\mathrm{BWT}_{\mathrm{m}}, \mathrm{kg}$ & $-0.16(0.29)$ & $0.43(0.38)$ & $0.15(0.08)$ & \\
$\mathrm{CD}_{\mathrm{m}}$ & $0.11(0.37)$ & $0.10(0.42)$ & $-0.42(0.53)$ & $0.13(0.08)$ \\
\hline
\end{tabular}

${ }^{1} \mathrm{BWT}_{\mathrm{r}}=$ birth weight residual; $\mathrm{CD}_{\mathrm{r}}=$ calving difficulty residual; $\mathrm{BWT}_{\mathrm{d}}=$ birth weight direct; $\mathrm{CD}_{\mathrm{d}}=$ calving difficulty direct; $\mathrm{BWT}_{\mathrm{m}}=$ birth weight maternal; $\mathrm{CD}_{\mathrm{m}}=$ calving difficulty maternal.

${ }^{2}$ Heritability (SE) are on the diagonal and correlations are on the off diagonal. 
Table 4. Birth weight breed differences estimated from USMARC data adjusted for sire sampling

\begin{tabular}{|c|c|c|c|c|}
\hline \multirow[b]{2}{*}{ Breed } & \multicolumn{2}{|c|}{ Average base EBV } & \multirow[b]{2}{*}{$\begin{array}{l}\text { BreedSoln }{ }^{3} \text { at USMARC (vs. Angus) } \\
\text { (3) }\end{array}$} & \multirow[b]{2}{*}{$\begin{array}{c}\text { BY } 2012 \text { breed difference }{ }^{4} \\
\text { (4) }\end{array}$} \\
\hline & $\begin{array}{c}\text { Breed } 2012^{1} \\
(1)\end{array}$ & $\begin{array}{l}\text { USMARC bulls }^{2} \\
(2)\end{array}$ & & \\
\hline$\overline{\text { Angus }}$ & 1.5 & 1.4 & 0 & 0.0 \\
\hline Hereford & 3.2 & 1.9 & 0.62 & $1.8(1.27)$ \\
\hline Red Angus & -1.1 & -2.2 & -2.71 & $-1.8(1.89)$ \\
\hline Shorthorn & 2.0 & 0.8 & 3.77 & $4.8(2.13)$ \\
\hline South Devon & 2.4 & 2.0 & 1.49 & $1.7(2.03)$ \\
\hline Beefmaster & 0.3 & 0.7 & 1.42 & $0.8(3.34)$ \\
\hline Brahman & 1.5 & 0.5 & 6.17 & $7.0(2.68)$ \\
\hline Brangus & 0.7 & 0.4 & -3.13 & $-3.0(4.24)$ \\
\hline Santa Gertrudis & 0.2 & 0.3 & 6.53 & $6.2(2.71)$ \\
\hline Braunvieh & 2.5 & 3.3 & 4.91 & $4.0(2.42)$ \\
\hline Charolais & 0.5 & -0.4 & 2.99 & $3.6(1.32)$ \\
\hline Chiangus & 3.4 & 2.6 & 0.61 & $1.2(2.66)$ \\
\hline Gelbvieh & 0.7 & 1.3 & -0.75 & $-1.5(1.83)$ \\
\hline Limousin & 1.5 & 0.9 & 1.95 & $2.4(1.28)$ \\
\hline Maine-Anjou & 1.5 & 1.7 & -3.11 & $-3.40(2.63)$ \\
\hline Salers & 1.5 & 1.5 & -5.17 & $-5.40(2.45)$ \\
\hline Simmental & 2.0 & 2.8 & 3.10 & $2.1(1.41)$ \\
\hline Tarentaise & 1.7 & 1.6 & -4.72 & $-4.8(4.71)$ \\
\hline
\end{tabular}

differ from those previously reported by Kuehn and Thallman (2014). There are several likely reasons for this discrepancy. The primary reason for this is because Kuehn and Thallman (2014) used mature cow data as well as the heifer data from this study for a total of over 30,000 BWT records. Additionally, the breeds with the largest changes between the studies included those in which over half of the phenotypes in the present study were generated from continuous GPE where heifers were bred back to their breed of sire from selected bulls chosen based on high (desirable) EBV for calving ease via AI, potentially creating partial confounding between direct and maternal breed effects. On the other hand, Kuehn and Thallman (2014) did not fit a maternal effect for BWT, and that may have biased some of the estimates, especially as the number of cows bred back to their breed of sire has increased in the GPE population. Yet another difference between the 2 analyses is that Kuehn and Thallman (2014) did not fit CD (direct and maternal) as a correlated trait.

Estimates of maternal breed effects on BWT were not reported because EBV of sampled sires (with which to adjust for sampling bias between breeds) were not available. Nonetheless, significant maternal breed effects on BWT have been previously reported. Bos indicus breeds have an especially important advantage in maternal effect on BWT (Freetly and Cundiff, 1998; Jenkins et al., 2000; Dillon et al., 2015).

Among the British breeds, Shorthorn calves were estimated to have the heaviest BWT whereas Red Angus calves were estimated to have the lightest BWT. Among the B. indicus-influenced breeds, Brahman were estimated to have the heaviest BWT and Brangus calves were estimated to have the lightest BWT. Roberson et al. (1986) and Comerford et al. (1987) reported that $B$. indicus sires increased BWT compared with Bos taurus sires when bred to B. taurus cows. Among the Continental breeds, Charolais calves were estimated to have the heaviest BWT and Salers and Tarentaise calves were estimated to have the lightest BWT. Cundiff et al. (1986) reported that high-growthrate breeds (Simmental, Maine-Anjou, Brahman, and Charolais) had heavier BWT whereas low-growth-rate breeds (Hereford, Angus, and South Devon) had lighter BWT. Estimates of breed effects show similar results except for Hereford, Simmental, and Maine-Anjou, where estimates suggest that Hereford have larger BWT than Simmental and Maine-Anjou in contrast to Cundiff et al. (1986) These differences reflect the changes in selection pressure by both Continental and British breeds that have occurred over time since Cundiff et al. (1986). 
Table 5. Calving difficulty score direct breed differences estimated from USMARC data adjusted for sire sampling

\begin{tabular}{|c|c|c|c|c|c|}
\hline \multirow[b]{2}{*}{ Breed } & \multicolumn{2}{|c|}{ Average base EBV } & \multirow[b]{2}{*}{$\begin{array}{c}\text { Additive genetic } \mathrm{SD}^{3} \\
\text { (3) }\end{array}$} & \multirow{2}{*}{$\begin{array}{c}\text { BreedSoln at USMARC } \\
\text { (vs. Angus })^{4} \\
(4)\end{array}$} & \multirow[b]{2}{*}{ BY 2012 breed difference } \\
\hline & $\begin{array}{c}\text { Breed 2012 } \\
\text { (1) }\end{array}$ & $\begin{array}{c}\text { USMARC bulls }^{2} \\
\text { (2) }\end{array}$ & & & \\
\hline$\overline{\text { Angus }}$ & -10.0 & -4.1 & 9.4 & 0.00 & 0.00 \\
\hline Hereford & -1.6 & 8.1 & 8.3 & $0.06(0.18)$ & $-0.13(0.06)$ \\
\hline Red Angus & -8.0 & -10.5 & 9.0 & $0.12(0.26)$ & $0.43(0.09)$ \\
\hline Brangus & -10.2 & -9.8 & 8.4 & $-0.04(0.60)$ & $0.16(0.21)$ \\
\hline Charolais & -6.0 & -3.9 & 14.2 & $0.59(0.18)$ & $0.76(0.06)$ \\
\hline Chiangus & -11.0 & -14.4 & 7.8 & $0.27(0.38)$ & $0.64(0.13)$ \\
\hline Gelbvieh & -19.4 & -14.2 & 7.8 & $0.17(0.26)$ & $0.16(0.09)$ \\
\hline Limousin & -18 & -18.8 & 8.6 & $0.52(0.18)$ & $0.77(0.06)$ \\
\hline Maine-Anjou & -18.4 & -13.7 & 7.8 & $0.40(0.37)$ & $0.41(0.13)$ \\
\hline Simmental & -18.6 & -10.5 & 7.8 & $0.41(0.20)$ & $0.27(0.07)$ \\
\hline
\end{tabular}

${ }^{1}$ The average within-breed EBV for each breed for birth year 2012 as reported by each respective breed association.

${ }^{2}$ The weighted average EBV as reported by each respective breed association of bulls for each breed having descendants with records at the U.S. Meat Animal Research Center (USMARC).

${ }^{3}$ The additive genetic SD for calving difficulty direct for each breed.

${ }^{4}$ BreedSoln = estimated breed effect solutions (SE) from analysis of USMARC data (Z-scores) with Angus set as the base.

${ }^{5}$ Estimated breed effects (SE) corrected for sire sampling and reported on the USMARC scale (Z-scores) for birth year (BY) 2012. Calculations: (5) $=\left((4) / \sigma_{a}+\{[(1)-(2)] /(3)\}\right)-\{[(1)-(2)] /(3)\}_{\text {Angus }} \times \sigma_{a}$, in which $\sigma_{a}$ is the direct additive genetic SD for calving difficulty estimated from the current analysis. Standard errors are the scaled SE from (4).

\section{Breed Effects for Calving Difficulty}

Breed effects for CD direct and maternal are presented in Tables 5 and 6, respectively. Breeds without estimates reflect breed associations that do not have $\mathrm{CD}$ direct and CD maternal EBV and include Shorthorn, South Devon, Beefmaster, Brahman, Santa Gertrudis, Braunvieh, Salers, and Tarentaise. Two Continental breeds, Limousin and Charolais, were estimated to have the largest breed effects for CD direct of 0.77 and 0.76, respectively. Of the British breeds, Red Angus was estimated to have the greatest degree of $\mathrm{CD}$ direct (0.43) whereas Hereford- and Angus-sired calves were estimated to require the least assistance at birth of all breeds analyzed. In terms of CD maternal, Red Angus- and Chiangus-sired heifers were estimated to have the most difficulty calving. However, larger Continental breeds such as Simmental-, Charolais-, Limousin-, and Maine-Anjou-sired heifers were estimated to have a fewer calving difficulties. Cundiff et al. (1986) reported that high-growth-rate breeds (Simmental, Maine-Anjou, and Charolais) experience more $\mathrm{CD}$ direct than low-growth-rate breeds (Hereford and Angus); the estimates of breed effects show similar results. Reynolds et al. (1990) reported that dams bred to large-size sire breeds experience more $\mathrm{CD}$ than dams bred to medium-size sire breeds.

Brangus is the only B. indicus-influenced breed in this study with EBV for CD. However, previous research has shown strong direct breed effects increasing $\mathrm{CD}$ in progeny of Brahman, Nellore, and
Boran sires bred to B. taurus cows but strong favorable maternal effects reducing $\mathrm{CD}$ in cows sired by these breeds (Cundiff et al., 1998; Freetly and Cundiff, 1998; Jenkins et al., 2000; Casas et al., 2011; Dillon et al., 2015).

\section{Challenges for Developing Across-Breed EBV Adjustments for Calving Difficulty}

An underlying issue relative to the development of across-breed EBV for CD direct and maternal is correctly accommodating the differences in models used by various beef breed associations in the estimation of EBV for these traits. All breeds use a multitrait model fitting BWT, but some use a linear-linear model and others use a threshold-linear model. Even within these 2 broad categories of model specification, other differences exist. Some breeds combine categories, thus shrinking the number of potential scores on a linear scale. For breeds that use a probit function treating $\mathrm{CD}$ as a threshold character, the point at which $\mathrm{CD}$ is centered on the underlying scale differs. Also, the mean incidence of difficulty (e.g., 50\%, 80\%, etc.) at which the back-transformed EBV is calculated from the underlying EBV can be different. To correctly estimate breed differences toward the development of adjustment factors for breeders to use when comparing animals of different breeds for $\mathrm{CD}$ direct and maternal, this larger issue of scaling must be addressed. Differences due to sire sampling undoubtedly impact these estimates. For breeds where sampled sires' 
Table 6. Calving difficulty score maternal breed differences estimated from USMARC data adjusted for sire sampling

\begin{tabular}{|c|c|c|c|c|c|}
\hline \multirow[b]{2}{*}{ Breed } & \multicolumn{2}{|c|}{ Average base EBV } & \multirow[b]{2}{*}{$\begin{array}{l}\text { Additive genetic } \mathrm{SD}^{3} \\
\text { (3) }\end{array}$} & \multirow{2}{*}{$\begin{array}{c}\text { BreedSoln at USMARC } \\
\text { (vs. Angus) }{ }^{4} \\
\text { (4) }\end{array}$} & \multirow[b]{2}{*}{$\begin{array}{c}\text { BY } 2012 \text { breed difference } \\
\text { (5) }\end{array}$} \\
\hline & $\begin{array}{l}\text { Breed } 2012^{1} \\
\text { (1) }\end{array}$ & $\begin{array}{l}\text { USMARC bulls }{ }^{2} \\
\text { (2) }\end{array}$ & & & \\
\hline$\overline{\text { Angus }}$ & -16.0 & -7.5 & 11.2 & $0.00(0.00)$ & $0.00(0.00)$ \\
\hline Hereford & -2.2 & 9.8 & 9.1 & $0.17(0.13)$ & $0.04(0.03)$ \\
\hline Red Angus & -10.0 & -15.6 & 9.0 & $0.01(0.22)$ & $0.32(0.05)$ \\
\hline Brangus & -14.2 & -14.1 & 6.5 & $-0.08(0.41)$ & $0.09(0.09)$ \\
\hline Charolais & -7.4 & -3.9 & 13.4 & $-0.33(0.16)$ & $-0.22(0.04)$ \\
\hline Chiangus & 4.4 & -7.6 & 7.9 & $-0.15(0.42)$ & $0.36(0.09)$ \\
\hline Gelbvieh & -13.6 & -8.3 & 7.9 & $0.14(0.20)$ & $0.16(0.04)$ \\
\hline Limousin & -9.0 & -6.9 & 8.9 & $-0.29(0.16)$ & $-0.17(0.04)$ \\
\hline Maine-Anjou & -7.0 & -1.7 & 7.9 & $-0.17(0.31)$ & $-0.15(0.07)$ \\
\hline Simmental & -21.2 & -13.0 & 7.9 & $-0.21(0.34)$ & $-0.27(0.08)$ \\
\hline
\end{tabular}

${ }^{1}$ The average within-breed EBV for each breed for birth year 2012 as reported by each respective breed association.

${ }^{2}$ The weighted average EBV as reported by each respective breed association of bulls for each breed having descendants with records at the U.S. Meat Animal Research Center (USMARC)

${ }^{3}$ The additive genetic SD for calving difficulty maternal for each breed

${ }^{4}$ BreedSoln = estimated breed effect solutions (SE) from analysis of USMARC data (Z-scores) with Angus set as the base.

${ }^{5}$ Estimated breed effects (SE) corrected for sire sampling and reported on the USMARC scale (Z-scores) for birth year (BY) 2012. Calculations: (5) $=(5)$ $=\left((4) / \sigma_{a}+\{[(1)-(2)] /(3)\}\right)-\{[(1)-(2)] /(3)\}_{\text {Angus }} \times \sigma_{a}$, in which $\sigma_{a}$ is the maternal additive genetic SD for calving difficulty from the current analysis. Standard errors are the scaled SE from (4).

EBV deviated from their breed's mean, EBV of calves born in a reference year (e.g., 2011), estimates should be adjusted for the sampling bias. However, this requires rescaling. Furthermore, sires that were born several decades ago may have had CD recorded in some breeds but not in others. Genetic trend will be underestimated in breeds that began recording $\mathrm{CD}$ more recently, and the disparity in data between breeds could bias estimates of breed differences.

Implementation of existing across-breed EBV has been through a table of additive adjustment factors. The scaling differences between breeds make this approach problematic for CD. An updated delivery model (perhaps web based), using a similar method of scale by variance as reported in this study, would be required to effectively implement across-breed EBV for CD.

\section{Conclusions}

Both BWT and CD direct are moderately heritable and, therefore, would favorably respond to direct selection. However, maternal effects are less heritable. Birth weight explained $41 \%$ of the genetic variation in $C D$, suggesting that BWT is a valuable indicator trait, but does not explain all of the genetic variation of the economically relevant trait of CD. Selecting bulls to reduce dystocia in their calves will have little effect on difficulty their daughters may experience when they calve. Therefore, both CD direct and maternal should be included in the breeding objective. Angus-, Hereford-,
Simmental-, Gelbvieh-, and Tarentaise-sired calves would be the least likely to experience $\mathrm{CD}$, whereas Braunvieh-, Shorthorn-, Salers-, and Limousin-sired calves would be the most likely to have dystocia issues. Hereford-, Salers-, and Tarentaise-sired heifers would be the most likely to have calves born unassisted, whereas Braunvieh-, Red Angus-, and Chiangus-sired heifers would be the most likely to have dystocia problems. Results show that the diverse biological types of cattle have different effects on both BWT and CD. Clearly, biological type delineation (British and Continental) is not the sole predictor in determining calving ease. Breeds with the most favorable effects for CD direct and maternal represent a mixture of biological types. These differences can be used to match breeds to complement needs of production systems. Issues to be resolved to develop an across-breed adjustment for CD direct and maternal includes accounting for different models used by breed associations. Some breed associations use a linear model and some use a threshold model. Among breed associations that use linear models, there can be differences between the number of categories that are used and the incidence rates for each category. Among breed associations using a threshold model, there are differences in the incidence rates, where centering occurred on the underlying scale, and the number of categories used. Scaling factors need to be developed to account for these differences. This work will serve as the foundation for the estimation of across-breed EBV for CD in the Unites States. 


\section{LITERATURE CITED}

Arango, J. A., L. V. Cundiff, and L. D. Van Vleck. 2002. Breed comparisons of Angus, Brahman, Hereford, Pinzgauer, Sahiwal, and Tarentaise for weight adjusted for condition score, height, and body condition score. J. Anim. Sci. 80:3142-3149.

Bellows, R. A., R. E. Short, D. C. Anderson, and B. W. Knapp. 1971. Cause and effect relationships associated with calving difficulty and calf birth weight. J. Anim. Sci. 33:407-415.

Bennett, G. L., and K. E. Gregory. 1996. Genetic (co)variances among birth weight, 200-day weight, and postweaning gain in composite and parental breeds of beef cattle. J. Anim. Sci. 74(11):2598-2611

Bennett, G. L., and K. E. Gregory. 2001. Genetic (co)variances for calving difficulty score in composite and parental populations of beef cattle: I. Calving difficulty score, birth weight, weaning weight, and postweaning gain. J. Anim. Sci. 79:45-51.

Brinks, J. S., J. E. Olson, and E. J. Carroll. 1973. Calving difficulty and its association with subsequent productivity in Herefords. J. Anim. Sci. 36:11-17.

Casas, E., R. M. Thallman, and L. V. Cundiff. 2011. Birth and weaning traits in crossbred cattle from Hereford, Angus, Brahman, Boran, Tuli, and Belgian Blue sires. J. Anim. Sci. 89:979-987. doi:10.2527/jas.2010-3142

Comerford, J. W., J. K. Bertrand, L. L. Benyshek, and M. H. Hohnson. 1987. Reproductive rates, birth weight, calving ease and 24-h calf survival in a four breed diallele among Simmental, Limousin, Polled Hereford, and Brahman beef cattle. J. Anim. Sci. 64:65-76.

Cundiff, L. V., K. E. Gregory, and R. M. Koch. 1998. Germplasm evaluation in beef cattle-Cycle IV: Birth and weaning traits J. Anim. Sci. 76:2528-2535.

Cundiff, L. V., K. E. Gregory, R. M. Koch, and G. E. Dickerson. 1986. Genetic diversity among cattle breeds and its use to increase beef production efficiency in a temperate environment. In: G. E. Dickerson and R. K. Johnson, editors, Proc. 3rd World Congr. Genet. Appl. Livest. Prod., Lincoln, NE. p. 271-282.

Cushman, R. A., M. F. Allan, R. M. Thallman, and L. V. Cundiff. 2007. Characterization of biological types of cattle (Cycle VII): Influence of postpartum interval and estrous cycle length on fertility. J. Anim. Sci. 85:2156-2162. doi:10.2527/jas.20070136

Dillon, J. A., D. G. Riley, A. D. Herring, J. O. Sanders, and R. M. Thallman. 2015. Genetic effects on birth weight in reciprocal Brahman-Simmental crossbred calves. J. Anim. Sci. 93:553561. doi:10.2527/jas.2014-8525

Eriksson, A., A. Näsholm, K. Johansson, and J. Philipsson. 2004. Genetic parameters for calving difficulty, stillbirth, and birth weight for Hereford and Charolais at first and later parities. J. Anim. Sci. 82:375-383.

Federation of Animal Science Societies (FASS). 1999. Guide for the care and use of agriculture animals in agriculture research and teaching. FASS, Savoy, IL.

Freetly, H. C., and L. V. Cundiff. 1998. Reproductive performance, calf growth, and milk production of first-calf heifers sired by seven breeds and raised on different levels of nutrition. J. Anim. Sci. 76:1513-1522.
Gilmour, A. R., B. J. Gogel, B. R. Cullis, and R. Thompson. 2009. ASReml user guide release 3.0. VSN Int. Ltd., Hemel Hempstead, UK.

Gregory, K. E., L. V. Cundiff, G. M. Smith, D. B. Laster, and H. A. Fitzhugh Jr. 1978. Characterization of biological types of cattle-cycle II: I. Birth and weaning traits. J. Anim. Sci. 47:1022-1030

Jenkins, T. G., C. L. Ferrell, and A. J. Roberts. 2000. Lactation and calf weight traits of mature crossbred cows fed varying daily levels of metabolizable energy. J. Anim. Sci. 78:7-14.

Kuehn, L. A., and R. M. Thallman. 2014. Across-breed EPD tables for the year 2014 adjusted to breed differences for birth year 2012. In: Beef Improv. Fed. Res. Annu. Meet., Lincoln, NE. p. 1-27.

Mujibi, F. D. N., and D. H. Crews Jr. 2009. Genetic parameters for calving difficulty, gestation length, and birth weight in Charolais cattle. J. Anim. Sci. 87:2759-2766. doi:10.2527/ jas.2008-1141

Northcutt, S. L., and D. E. Wilson. 1993. Genetic parameter estimates and expected progeny differences for mature size in Angus cattle. J. Anim. Sci. 71:1148-1153.

Notter, D. R., and L. V. Cundiff. 1991. Across-breed expected progeny differences: Use of within-breed expected progeny differences to adjust breed evaluations for sire sampling and genetic trend. J. Anim. Sci. 69:4763-4776.

Reynolds, W. L., J. J. Urick, and B. W. Knapp. 1990. Biological type effects on gestation length, calving traits, and calf growth rate. J. Anim. Sci. 68:630-639.

Roberson, R. L., J. O. Sanders, and T. C. Cartwright. 1986. Direct and maternal genetic effects on preweaning characters of Brahman, Hereford, and Brahman-Hereford crossbred cattle. J. Anim. Sci. 63:438-446.

Smith, G. M., D. B. Lester, and K. E. Gregory. 1976. Characterization of biological types of cattle 1. Dystocia and preweaning growth. J. Anim. Sci. 43:27-36.

Snelling, W. M., M. F. Allan, J. W. Keele, L. A. Kuehn, T. McDaneld, T. P. L. Smith, T. S. Sonstegard, R. M. Thallman, and G. L. Bennett. 2010. Genome-wide association study of growth in crossbred cattle. J. Anim. Sci. 88:837-848. doi:10.2527/ jas.2009-2257

Van Vleck, L. D., L. V. Cundiff, T. L. Wheeler, S. D. Shackelford, and M. Koohmaraie. 2007. Across-breed adjustment factors of expected progeny differences for carcass traits. J. Anim. Sci. 85:1369-1376. doi:10.2527/jas.2006-658

Wheeler, T. L., L. V. Cundiff, S. D. Shackelford, and M. Koohmaraie. 2001. Characterization of biological types of cattle (Cycle V): Carcass, yield, and longissimus palatability traits. J. Anim. Sci. 79:1209-1222.

Wheeler, T. L., L. V. Cundiff, S. D. Shackelford, and M. Koohmaraie. 2004. Characterization of biological types of cattle (Cycle VI): Carcass, yield, and longissimus palatability traits. J. Anim. Sci. 82:1177-1189.

Wheeler, T. L., L. V. Cundiff, S. D. Shackelford, and M. Koohmaraie. 2010. Characterization of biological types of cattle (Cycle VIII): Carcass, yield, and longissimus palatability traits. J. Anim. Sci. 88:3070-3083. doi:10.2527/jas.2009-2497 